\title{
Residential Differentials in Incidence of Juvenile Delinquency in Ijaiye Low Cost Housing Estate, Lagos, Nigeria
}

\author{
ADIGUN Folasade Oyenike *ABOLADE Olajoke, \\ AKINDELE Oluremi Akinropo IGE, James Olateju OGUNTUYI Dolapo Ikeoluwapo \\ AKINBAMI Babatunde Saheed \\ Department of Urban and Regional Planning, \\ Ladoke Akintola University of Technology, Ogbomoso, Nigeria \\ *Corresponding Author
}

\begin{abstract}
Within the framework of the three residential areas, this study investigated the variation in the incidence, causes, and fear of juvenile delinquency in Ijaiye Low Cost Housing Estate, Lagos. Using random systematic sampling 199 copies of a structured questionnaire were distributed in the selected localities in a ratio of 3:2:1 among the three residential densities. An index termed Incidence of Juvenile Delinquency (IJD) was used in measuring the level of occurrence of twenty crime types in the study area. Other indices developed in the study included Causes of Juvenile Delinquency (CJD); Fear of Crime Incidence Index (FDI); Effectiveness of Delinquency Control Measures Index (EDCMI). CJD was used to measure residents' perceived causes of juvenile delinquency, FDI was developed to investigate residents' perceived feelings of fear of juvenile delinquency while EDCMI was used to measure the effectiveness of control measures used by adult residents' in curbing delinquency in their zones. It was observed that smoking ( $\mathrm{IJD}=2.86)$, cultism $(\mathrm{IJD}=0.64)$ and reckless endangerment $(\mathrm{IJD}=0.21)$ had the highest IJD recorded in high, medium and low density residential area respectively. The observed variation in incidence of juvenile delinquency is significant among the three residential areas in the Estate $(\mathrm{F}=516.050, \mathrm{p}=$ 0.000). Influence of peer group and social media each with CJD of 1.23 were perceived as the major causes of delinquency in Ijaiye Low Cost Housing Estate. Adults residents had higher fear of property being destroyed, being attacked early in the morning and at night due to the reduced level of police patrol in the area. The level of fear of delinquency in the high density (FDI = 1.81) was more than twice the level of fear in the study area (FDI $=0.79)$ while the medium density $(\mathrm{FDI}=0.45)$ had almost four times that of the low density area $(\mathrm{FDI}=0.12)$. The study concluded that the level of incidence and fear of delinquency decreased from the high to the low density area. The study suggests that areas of high incidences and impact should receive greater attention in the provision of any intervention while other areas must not be neglected.
\end{abstract}

DOI: $10.7176 / \mathrm{DCS} / 9-9-05$

Publication date:September $30^{\text {th }} 2019$

\section{INTRODUCTION}

The problem of juvenile delinquency is a burning issue of concern all over the world. The population of delinquents is not only increasing, a cursory observation shows a significant reduction in the lower limit of the delinquents' age bracket. This indicates that younger children are getting more involved in delinquent activities. Besides the persistence of the problem, it is increasing in intensity, severities and impacts involving the use of new techniques and instruments. This is considered lethal for the prosperity of any country and the whole world considering the economic value of crime committed and the burden of rehabilitation of delinquents on the resources of the nation.

Who is a juvenile? A juvenile is a person not fully grown or developed (Dictionary Thesaurus Accessed 0107-2013). The laws of different nations stipulated different age brackets for the juveniles. The concept of a juvenile is sometimes used interchangeably with other concepts like a child, an adolescent and a youth. The age limit and the meaning of juvenile delinquency vary in most countries, but it is generally below 18 years. A juvenile delinquent is one who is a minor with major problems. What is considered a delinquent behavior in a country may be an acceptable behavior in another part of the world; however juvenile delinquency refers to the violation of the criminal codes regulating the behavior of young persons in the society. It is basically an anti-social behavior (Thornberry et al 2004). Juvenile delinquency as broadly defined refers to any act in violation of criminal law, committed by a person defined under law as juvenile, which if it had been committed by an adult will be treated as crime or criminal conduct (Alemika 1978; Muncie 1999).

According to the developmental research of Moffitt (2006), there are two types of offenders that emerge in adolescence. One is the repeat offender referred to as the life-course-persistent offender, who begins offending or showing antisocial/aggressive behavior in adolescence (or even childhood) and continues into adulthood. The second type is the age specific offender, referred to as the adolescence-limited offender, for whom juvenile offending or delinquency begins and ends during their period of adolescence. As a result of the fact that most teenagers tend to show some form of antisocial or delinquent behavior during adolescence, it is important to account for these behaviors in childhood in order to determine whether they will be life-course-persistent offenders or adolescence-limited offenders (Scott, 2009). Although adolescence-limited offenders tend to drop all criminal 
activity once they enter adulthood and show less pathology than life-course-persistent offenders, they still show more mental health, substance abuse, and finance problems, both in adolescence and adulthood, than those who were never delinquent (Aguilar et al, 2000).

It has been established on a broader level that crime as a human activity, though negative occur not only within the environment, but are also influenced and may indeed be compounded by a wide ranging socio-economic and environmental factors, summarized in urban environment (Abodunrin, 2004; Adigun, 2012). In the same vein it is argued here that there are intricate connection and complex interrelationships between the environment in which delinquents live, incidence of juvenile delinquency and, by logical extension, response to it. It has been observed that urban environment are characterized with different socio-economic, socio-cultural and physical/environmental factors, which have various implications for, and impacts on the type as well as the rate of occurrence of juvenile delinquency (Shaw and McKay, 1942; Davidson 1981; Charron, 2012). These types of delinquency can be traced to various factors that are inherent in residential neighborhood structure such as dense population, unemployment, inadequate shelter and housing, inadequate provision of social services, poverty and inability of the educational system to respond to new challenges (Shaw et al, 1969). The negative influence of commercialized mass media featuring obscene and violent movies which has the tendency to stimulate juvenile into practice of what is seen or watched is another significant causes of delinquency. Breakdown of family unit is another serious cause of juvenile delinquency. Studies have revealed that family is a major predictor of delinquency (Mandara and Murray, 2006). According to Simons, Simons and Wallace (2004) children in single-parent homes are more likely to be delinquent. There is evidence to suggest that single-parent families, especially single-mothers, expect less of their children, spend less time monitoring them and use less effective techniques to discipline them. This means that children have greater opportunities and motivation to participate in delinquent acts than do those living in a two-parent family. Hence, the absence of one parent is a major predictor for juvenile delinquency (Mack et al., 2006).

The peer group is another delinquency predisposing factor as it creates opportunities outside family situation for children to commit crime. Peers are individuals with whom a youth shares common problems and experiences. The peer group is a convenient structure which is suitable for the needs of emotionally disturbed children who are unable to meet the demands required for participation in normal groups. Aggressive adolescents rejected by peers are likely to have a "hostile attribution bias", which leads people to interpret the actions of others (whether they be hostile or not) as purposefully hostile and aggressive towards them thus often resulting in an impulsive and aggressive reaction (Dodge, 2003). Poor performance in school may increase the chances of offending because low educational attainment, a low attachment to school, and low educational aspirations are all risk factors for offending in themselves (Walklate et al, 2003). Children who perform poorly at school are also more likely to be truant, and the status offense of truancy is linked to further offending (Farrington, 2002).

The perceived and observed severity of crime in cities coupled with such underlying factors as individualism, alienation and poverty syndrome, which accompany the growth of big and impersonal cities, might have led to the enormous concentration of research efforts on them (Obateru, 1994; Albert, 1996; Agbola, 1997; Afon, 2001; Agbola, 2002; Oredein, 2006). Despite the research efforts and the resulting policy and programmes, the problem does not only persist, it increases in intensity, impact and severities, involving the use of new techniques and instruments but also the perpetrators are becoming more intrepid and ferocious. Past research efforts by the singular act of concentrating on crime, had first, neglected the younger stage which is juvenile delinquency and thus largely incapable of suggesting policies that could tackle the problem when it is yet fully blown into crime. Given this social malady an early attention would have saved the nation a lot of waste of resources and blessed youthful minds who could have contributed immensely to national development if their antisocial behaviour was effectively curtailed and did not graduated to crime. To this end the study examines the incidence of, and perceived level of fear and residents' response to juvenile delinquency among the three residential densities in Ijaiye Low Cost Housing Estate, Lagos.

\section{STUDY AREA}

The study area is Ijaiye Low Cost Housing Estate which is located in Agege Local Government Area, north western part of Lagos State. It lies approximately between the longitude 313'30'E to 3 17' 15' E and latitude 628 'N to 6 42 'N (Agege master plan, 2009). Towards the east it is bounded by Ikeja while on the south, the study area is bounded by Oshodi/ Isolo area of Lagos State. The study area is a planned residential neighborhood. Even though it is called a Low Cost Residential Estate, it has high, medium and low residential densities. High density is divided into six zones which include Abuja, Unity, Pen Cinema, Rehoboth, Peace and Green Earth zones while medium density is divided into three zones which include Phase 1, Phase 2 and Phase 3. Low density has just one zone which is referred to as G.R.A.

\section{RESEARCH METHODOLOGY}

The target population was the residents and juveniles. The study utilized primary data obtained through a structured 
questionnaire administered to residents of Ijaiye Low Cost Housing Estate, Lagos State. Information obtained includes residents' socioeconomic characteristics; incidences, causes, fear and control measures of juvenile delinquencies in Ijaiye low cost housing estate. The three residential densities were clearly identified in the study area. The high residential area was made up of the six zones with 54 blocks in each zone and six flats in one block. The medium residential area consisted of 3 zones with 20 blocks in each zone and four flats in a block. The third zone was the low residential area with 30 houses. Three, two and the only zone (s) were purposively sselected in the high, medium and low density residential area. Questionnaires were administered to residents using the systematic sampling method. This involves the choice of the third house on each selected streets in the selected zone then subsequent buildings were chosen at an interval five buildings. The choice of respondent was based on the availability at the time of survey. There was no gender bias as both male and female respondents were accommodated in the survey. A respondent not less than 18 years either male or female was sampled in each selected building.

Juveniles were sampled from a government owned Secondary School: Keke Senior High School. The school had Senior Secondary Class I consisting of 11 arms, while classes II and III have 5 arms each respectively. Five and two arms each were respectively selected from SSI and SS II and III. Fifteen percent of the total population in the selected arms was sampled. Juveniles not less than 13-18 years were selected from the selected Secondary School in the estate. A total of 120 and 79 copies of the questionnaire was distributed to and recovered from adult residents and juveniles. This represent 100 percent recovery rate.

Data analysis was mainly descriptive. Four indices were developed in this study. The first was an index termed: Incidence of Juvenile Delinquency (IJD) which was used in measuring the level of occurrence of twenty delinquency types in the study area. Other indices developed in the study included Causes of Juvenile Delinquency (CJD); Fear of Delinquency Index (FDI); Effectiveness of Delinquency Control Measures Index (EDCMI). CJD was used to measure residents' perceived causes of juvenile delinquency, FDI was developed to investigate residents' perceived feelings of fear of juvenile delinquency while EDCMI was used to measure the perceived level of effectiveness of control measures used by adult residents' in curbing delinquency in their zones.

Variables for which indices were developed were measured in ranking scale of Likert as "very high" (5), "high"(4), "moderate (3)", "low"(2) and "very low"(1). The indices were obtained by dividing the summation of weighted value (SWV) by the total number of responses. The SWV of each variable is the addition of the product of the proportion of responses to it and the weighted value attached to each rating. This was done for each residential area. The mathematical expression is as follows:

$\mathrm{X}=\mathrm{SWV} / \mathrm{Ni}(1)$

$\mathrm{SWV}=\mathrm{NiVi}(2)$

Where: SWV = Summation of weight value

$\mathrm{Ni}=$ Number of Respondents rating variable $\mathrm{i}$; and

$\mathrm{Vi}=$ weight assigned to variable $\mathrm{i}$

$\mathrm{X}$ could be IJD = 'Incidences of Juvenile Delinquency'; CJD= 'Causes of Juvenile Delinquency'; FDI= 'Fear of Delinquency Index'; EDCMI= 'Effectiveness of Delinquency Control Measure Index'.

Table 1: Distribution of Questionnaire among Adult Residents

\begin{tabular}{|l|l|l|l|}
\hline SN & Residential Density & Residential Zones & No of Questionnaire \\
\hline \multirow{2}{*}{1} & \multirow{2}{*}{ High } & Abuja & 32 \\
\cline { 3 - 4 } & & Unity & 30 \\
\cline { 3 - 4 } & & Pen Cinema & 32 \\
\cline { 3 - 4 } & & Total & 94 \\
\hline \multirow{2}{*}{2} & \multirow{2}{*}{ Medium } & Phase 2 & 12 \\
\cline { 3 - 4 } & & Phase 3 & 8 \\
\cline { 3 - 4 } & & Total & 20 \\
\hline 3 & Low & GRA & 6 \\
\hline & Total & & 120 \\
\hline
\end{tabular}

Source: Author's 2016

Table 2: Distribution of Questionnaire among Juveniles

\begin{tabular}{|l|l|l|}
\hline S/N & Class & Number of Questionnaire \\
\hline $\mathbf{1}$ & SSI & 35 \\
\hline $\mathbf{2}$ & SSII & 25 \\
\hline $\mathbf{3}$ & SSIII & 19 \\
\hline & Total & 79 \\
\hline
\end{tabular}

Source: Author's 2016 


\section{RESULT AND DISCUSSION}

\section{Incidence of Juvenile Delinquency}

Smoking (IJD = 3.52), theft (IJD =2.99) and truancy (IJD =2.77) were the prominent delinquencies in the study area. The observed variation in incidence of juvenile delinquency is significant among the three residential areas in the Estate $(\mathrm{F}=516.050, \mathrm{p}=0.000)$. This implies that the incidence of certain delinquency is prominent in some residential areas than the other. In the high density residential area smoking had the highest incidence with IJD index value of 2.86. This indicated that there was high level of smoking in the high density area. Next in rank were theft and alcohol offences with occurrence indexes of 2.39 and 2.34 respectively. However, reckless endangerment had the lowest level of incidence in the area with an IJD index value of 1.53. In the medium density area, it was observed that cultism, attack on people going out early and coming in late were the dominant delinquencies found in the area with IJD index values of $0.64,0.52$ and 0.50 respectively. Fraud and reckless endangerment with IJD of index value of 0.28 were the least committed delinquent acts in the zone.

Reckless endangerment and smoking each with IJD index value of 0.21 and alcohol offences (IJD $=0.18$ ) were found to be dominating in the low density area. According to residents this resulted from the infiltration of children from a nearby slum to the low cost housing (see Table 3). Delinquent acts such as curfew violation, harassment of residents, and criminal attack on people going out early or late were the delinquencies with the least level of incidences in the zone. The juveniles indicated that cultism, mischief/criminal nuisance (picking flowers from restricted area) were prominent delinquencies while drug abuse, smoking and rape were found not to be so common in the school environment and the whole Ijaiye Estate.

Table 3: Residential Differential in Perceived level of Incidence of Juvenile Delinquency in Ijaiye Low Cost Housing Estate

\begin{tabular}{|c|c|c|c|c|c|c|c|}
\hline \multirow[t]{2}{*}{$\mathbf{S} / \mathbf{N}$} & \multirow[t]{2}{*}{ Incidences of Juvenile Delinquency } & \multicolumn{3}{|c|}{$\begin{array}{l}\text { IJD for Residential } \\
\text { Areas }\end{array}$} & \multirow[t]{2}{*}{ IJD } & \multirow[t]{2}{*}{$\begin{array}{l}\text { IJD- } \\
\text { *IJD }\end{array}$} & \multirow[t]{2}{*}{$\begin{array}{l}\text { (IJD- } \\
\left.{ }^{*} \text { IJD }\right)^{2}\end{array}$} \\
\hline & & High & Medium & Low & & & \\
\hline 1. & Theft & 2.39 & 0.44 & 0.16 & 2.99 & 0.51 & 0.26 \\
\hline 2. & Truancy & 2.19 & 0.43 & 0.15 & 2.77 & 0.29 & 0.08 \\
\hline 3. & Smoking & 2.86 & 0.45 & 0.21 & 3.52 & 1.04 & 1.08 \\
\hline 4. & $\begin{array}{l}\text { Female gender being raped at late } \\
\text { hours/anytime }\end{array}$ & 1.65 & 0.39 & 0.13 & 2.17 & -0.31 & 0.10 \\
\hline 5. & Violence & 1.91 & 0.42 & 0.13 & 2.46 & -0.02 & 0.00 \\
\hline 6. & Attack on people going out early & 1.83 & 0.52 & 0.10 & 2.45 & -0.03 & 0.00 \\
\hline 7. & Attack on late hour movement & 1.92 & 0.50 & 0.10 & 2.52 & 0.04 & 0.00 \\
\hline 8. & Prostitution & 1.79 & 0.34 & 0.13 & 2.26 & -0.22 & 0.05 \\
\hline 9. & Fighting & 2.22 & 0.39 & 0.15 & 2.76 & 0.28 & 0.08 \\
\hline 10. & Rioting & 1.82 & 0.31 & 0.12 & 2.25 & -0.23 & 0.05 \\
\hline 11. & Cultism & 1.73 & 0.64 & 0.13 & 2.5 & 0.02 & 0.00 \\
\hline 12. & Drug abuse & 1.78 & 0.34 & 0.16 & 2.28 & -0.2 & 0.04 \\
\hline 13. & Harassment of residents & 1.89 & 0.42 & 0.10 & 2.41 & -0.07 & 0.00 \\
\hline 14. & Alcohol offences & 2.34 & 0.41 & 0.18 & 2.93 & 0.45 & 0.20 \\
\hline 15. & Vandalism & 2.08 & 0.44 & 0.09 & 2.61 & 0.13 & 0.02 \\
\hline 16. & Curfew violation & 1.62 & 0.33 & 0.10 & 2.05 & -0.43 & 0.18 \\
\hline 17. & Mischief/criminal nuisance & 1.67 & 0.33 & 0.11 & 2.11 & -0.37 & 0.14 \\
\hline 18. & Fraud & 1.80 & 0.28 & 0.15 & 2.23 & -0.25 & 0.06 \\
\hline 19. & Loitering & 1.93 & 0.32 & 0.17 & 2.42 & -0.06 & 0.00 \\
\hline 20. & Reckless endangerment & 1.53 & 0.28 & 0.21 & 2.02 & -0.46 & 0.21 \\
\hline & Total & 38.94 & 7.98 & 2.77 & 49.71 & & \\
\hline & *IJD & 1.95 & 0.39 & 0.14 & & & \\
\hline
\end{tabular}

Source: Author's Field Survey, 2016

\section{The Causes of Juvenile Delinquency}

Influence of peer group and social media each with CJD of 1.23 are perceived as the major causes of delinquency in Ijaiye Low Cost Housing Estate. Next in rank is the influence of entertainment media with CJD index value of 1.17. Peer group $(\mathrm{CJD}=2.98)$ and social media $(\mathrm{CJD}=2.85)$ were found to be the major causes of juvenile delinquency in the high density area (Table 4). Next to these were the entertainment media and parents not paying enough attention to the children each with a CJD value of 2.69. It was further observed that majority of the respondents were hardly around to do the local community policing of the environment during the broad daylight. The least cause of delinquency indicated in the high density zone of the estate included design of buildings within 
the area with CJD of 1.68 , absence of functioning parks $(\mathrm{CJD}=1.83)$ and lack of sporting facilities with CJD index value of 1.85 .

In the medium density area, residents attributed delinquent act to teachers not paying enough attention to students $(\mathrm{CJD}=0.70)$ and the absence of functioning parks $(\mathrm{CJD}=0.70)$ and sporting facilities $(\mathrm{CJD}=0.70)$ where juveniles could exhaust their energies during the day such that they would hardly have time to think of evil. Among causes with least index was design of buildings within the area with CJD of 0.41 . This was because the estate was a planned residential environment with distinct building design. Ineffective policing of the area and absence of security measures were also considered to be of minimal contribution to incidence of delinquency in the area. This was probably attributed to the fact that the entrance to the medium density area was manned by security guard hired by the community.

Social media network $(\mathrm{CJD}=0.21)$ was considered to have the highest contribution to delinquency in the low density area. Next to this was family impact, peer group influence each with CJD of 0.20 . Lack of sporting facilities, teacher's not paying attention to students and presence of dark staircase for those living in storey buildings were all considered to be of little contribution to juvenile delinquency in the area. This result was in consonance with the previous findings in the literature (Wallace, 2004; Mack et al, 2006). Access to social media by children of the affluent is not strange since the parents have the financial capability.

Considerable proportion of residents $(72.5 \%)$ indicated that delinquencies were majorly committed by juvenile within the age brackets of $17-18$ years. Next to this were $26.7 \%$ of the residents who associated delinquency to juveniles of 14-16 years. Only a minor proportion (0.8\%) indicated that juveniles of 11-13 years prominently involved in delinquency. Juveniles of 17-18 years were generally observed to be secondary school leavers or students at the early stage of their studies in the higher institution. This suggested that young secondary school leavers (17-18 years) awaiting admission into the university were found to be more involved in delinquent act as a result of idleness and transition into young adults.

From the view of juvenile, peer group influence $(\mathrm{CJD}=2.20)$, social media $(\mathrm{CJD}=2.11)$ and the neighbourhood environmental factors $(\mathrm{CJD}=2.09)$ were all considered to be among the major causes of juvenile delinquency in the estate. Variables such as teachers not paying attention to students, absence of security guard were considered as the least causes of juvenile delinquency in the area. To corroborate this it was observed that the school gate was manned by security guard thus movements of students are controlled.

Table 4: Perceived Causes of Juvenile Delinquency in the Three Residential Densities Area

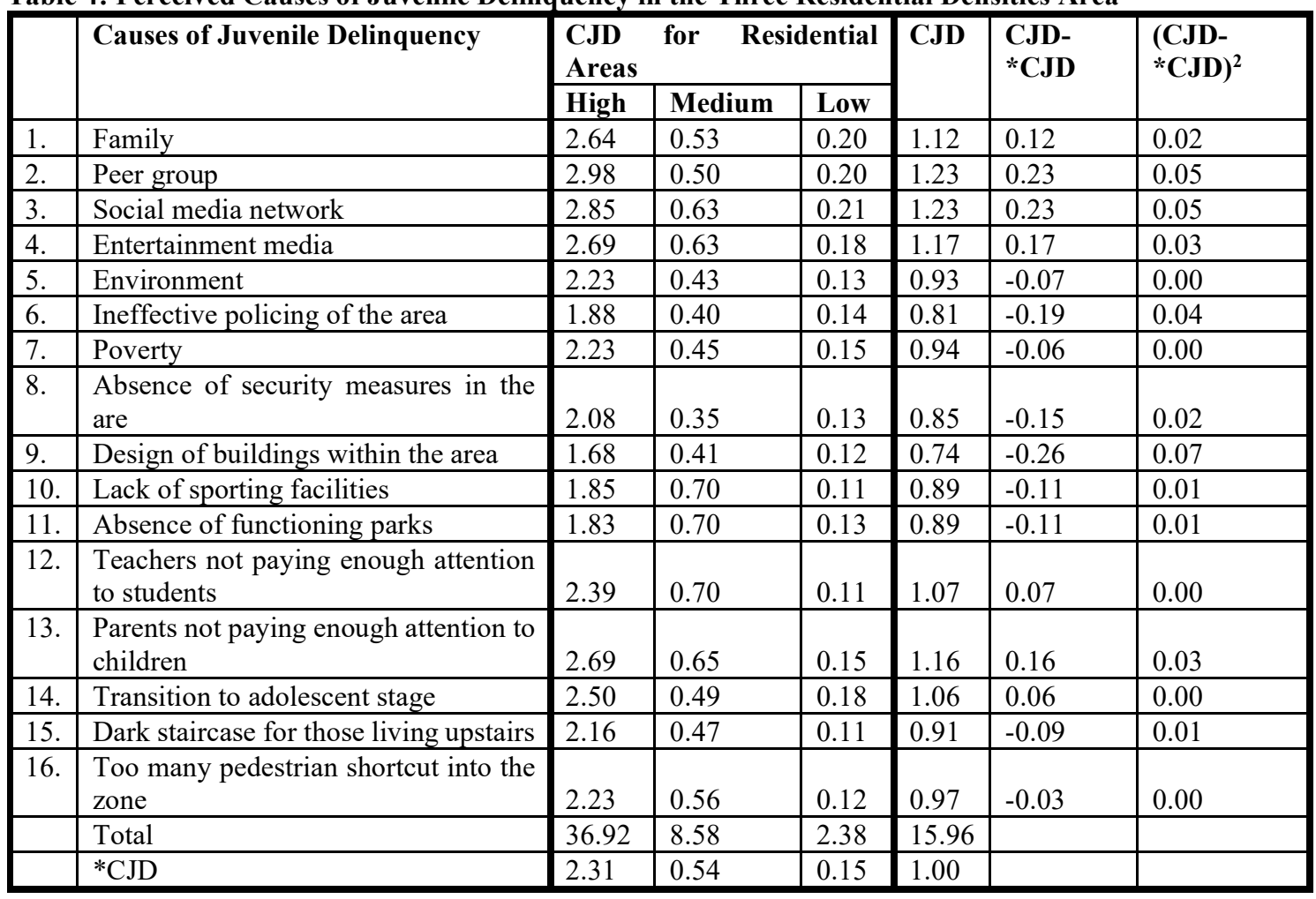

Source: Author's Field Survey, 2016

The Effects of Juvenile Delinquency

Residents living in the high density area of Ijaiye Low Cost Housing Estate had high level of fear of their properties 
being carted away by criminals (2.03). Other feelings with high FDI were 'fear of being attacked late in the night' $(\mathrm{FDI}=1.98)$; fear of being attacked early in the morning $(\mathrm{FDI}=1.93)$; fear of walking alone in the Estate (FDI= 1.88). These feelings could be attributed to the fact that majority of the adults had their workplace close by and tend to return late at night. Theft being one of the delinquencies with a high occurrence index in the high density confirmed their feelings.

Adults in the medium density zone of Ijaiye Low Cost Housing had more fear of being attacked late in the night, fear of being attacked early in the morning each with FDI of 0.53 . Next to this was fear of being raped (FDI= $0.48)$; fear of been harassed $(\mathrm{FDI}=0.48)$ and fear of property being destroyed $(\mathrm{FDI}=0.45)$ as shown in Table 5 . This was a much expected feeling from adult residents because cultism and other forms of criminal activities were on a high level in the medium density.

Adult residents living in the low density had feelings of property being stolen with FDI value of 0.16 . Next in rank was fear of unknown $(\mathrm{FDI}=0.15)$ and feelings of being stoned by juveniles $(\mathrm{FDI}=0.15)$. It was of no surprise that most of the residents in this zones experienced fear of property being stolen because the rich were always considered to have lots of high-quality assets with high secondhand value. Smoking had a high occurrence index in the low density area and it sometimes made juvenile misbehave or become irrational or do things out of the norms which may create fear in the heart of residents of Ijaiye Low Cost Housing.

The level of fear of delinquency in the high density (FDI =1.81) was more than twice the level of fear in the study area $(F D I=0.79)$ while the medium density $(F D I=0.45)$ had almost four times that of the low density area $($ FDI $=0.12$ ). It was also observed that some feelings of fear within the residential areas have FDI value either above or below the mean FDI value in the study area. On a general note all the variables used in measuring feelings of fear of delinquency in the high density had higher FDI than that the remaining two densities as well as the whole the study area. This implies that residents of the high density area had high level of fear of juvenile delinquency. This was probably due to the nature of the selected areas with considerable dense population. This indicative of high interpersonal contacts capable of engendering conflicts publicly in Nigeria. In the medium and low density areas all the variables had lower FDI values than the mean FDI value in the study area. This was indicative of low level of fear of delinquency in the area. This could be attributed to the fact that measurable level of control are put up in these areas.

The pattern of fear of crime events observed in Ijaiye Low Cost Housing Estate was in consonance with the perceived level of incidence of juvenile delinquency. The level of incidence decreased from the high to the low density areas (IJD for high $=1.95$; medium $=0.39$ and low $=0.14$ ). In the same vein level of fear of juvenile delinquency (FDI) experienced in the three residential areas decreased from the high to the low density area (FDI for high $=2.31$; medium $=0.54$ and low $=0.15$ ). Fear of crime events was at the lowest ebb in the low density where the lowest IJD was recorded while the high density had the highest level of incidence and fear of events associated with delinquency. This was considered normal; people who experience high level of delinquency would exercise high level of fear of such.

On the side of the juvenile, they tend to exercise high level of fear for being beaten, harassed and attacked. However, fear of walking alone with FDI of 2.38 was one of the least of fears experienced by them. These feelings of fear were evident as majority of the students indicated that they always held an amount of N100:00 - N300:00 which an older student could bully a younger one to collect either by force or coercion. Some of the students even reported that walking alone after school could be dangerous because residents who were juveniles were likely to attack them.

Table 5: Adults' Fear of Delinquency in the Three Residential Areas

\begin{tabular}{|c|c|c|c|c|c|c|c|}
\hline & \multirow[t]{2}{*}{ CRIME TYPES } & \multicolumn{3}{|c|}{ FDI for Residential Areas } & \multirow[t]{2}{*}{ FDI } & \multirow{2}{*}{$\begin{array}{l}\text { FDI- } \\
* \text { FDI }\end{array}$} & \multirow{2}{*}{$\begin{array}{l}(\text { FDI- } \\
* \text { FDI })^{2}\end{array}$} \\
\hline & & High & Medium & Low & & & \\
\hline 1. & $\begin{array}{l}\text { Fear of being attacked early in the } \\
\text { morning }\end{array}$ & 1.93 & 0.53 & 0.12 & 0.86 & 0.067 & 0.0045 \\
\hline 2. & Fear of being attacked late at night & 1.98 & 0.53 & 0.12 & 0.88 & 0.084 & 0.0070 \\
\hline 3. & Fear of being raped & 1.57 & 0.48 & 0.13 & 0.73 & -0.07 & 0.0044 \\
\hline 4. & Fear of being harassed & 1.83 & 0.48 & 0.12 & 0.81 & 0.017 & 0.0003 \\
\hline 5. & Fear of walking alone & 1.88 & 0.42 & 0.13 & 0.81 & 0.017 & 0.0003 \\
\hline 6. & Fear of property being destroyed & 1.85 & 0.45 & 0.07 & 0.79 & -0.003 & 0.0000 \\
\hline 7. & Fear of unknown & 1.87 & 0.37 & 0.15 & 0.80 & 0.004 & 0.0000 \\
\hline 8. & Fear of being stoned by juveniles & 1.34 & 0.39 & 0.13 & 0.62 & -0.173 & 0.0299 \\
\hline \multirow[t]{3}{*}{9.} & Fear of property being stolen & 2.03 & 0.46 & 0.16 & 0.88 & 0.090 & 0.0082 \\
\hline & TOTAL & 16.28 & 4.09 & 1.12 & 7.16 & & \\
\hline & $*$ FDI & 1.81 & 0.45 & 0.12 & 0.79 & & \\
\hline
\end{tabular}

Source: Author's Field Survey, 2016 
Effectiveness of Juvenile Control Measures in Ijaiye Low Cost Housing Estate.

Some measures were employed on individual or community basis to curb or control criminal and delinquency acts in the Estate. These included erection of fence around the estate and individual buildings, police patrol, community surveillance, watch pets, hired guard, gun, alarm system, special window/door lock and closed circuit television. The availability as well as functionality of these measures/facilities was considered in this study. The estate fence with the two gates at the entrance and exit of the area are considered most effective by residents at controlling the activities of delinquents in three residential areas. A cursory observation however revealed that there were no checking points at these gates. Residents of the three areas also considered their building fence, hired community guard and the use of special window and door locks more effective in preventing and or controlling juvenile delinquencies. Initial building designs had been altered to suit the security needs of individuals. People spent fortune on various security gadgets in order to protect themselves and their properties against juvenile delinquency. The possession and use of gun and close circuit television were not rated high in controlling delinquencies probably because the malady was not at an alarming rate in the area coupled with the emotionalism and sentiments that could be attached since these delinquents were probably children of residents in the Estate. Besides, disclosing the possession of these security items depended on individual's perception although some would like to disclose it to scare invaders, others would like to keep it secret for fear of being outsmarted. Police activities were not even rated high as the residents were skeptical about police protection. This posed further question on the confidence reposed in the ability and efficiency of Nigeria Police Force in curbing delinquency in the society.

Table 6: Residents' Perceived Level of Effectiveness of Control Measures used in the Three Residential Areas

\begin{tabular}{|c|c|c|c|c|c|c|c|}
\hline & \multirow[t]{2}{*}{ Safety Measures } & \multicolumn{3}{|c|}{ Residential Areas } & \multirow[t]{2}{*}{ EDCMI } & \multirow{2}{*}{$\begin{array}{l}\text { EDCMI- } \\
* \text { EDCMI }\end{array}$} & \multirow{2}{*}{$\begin{array}{l}\text { (EDCMI- } \\
{ }^{*} \text { EDCMI) }\end{array}$} \\
\hline & & High & Medium & Low & & & \\
\hline 1. & Estate fence & 3.11 & 0.69 & 0.18 & 1.33 & 0.31 & 0.10 \\
\hline 2. & Building fence & 2.97 & 0.69 & 0.17 & 1.28 & 0.26 & 0.07 \\
\hline 3. & Police patrol & 1.74 & 0.30 & 0.14 & 0.73 & 0.27 & 0.07 \\
\hline 4. & Community surveillance & 2.34 & 0.33 & 0.13 & 0.93 & 0.07 & 0.005 \\
\hline 5. & Watch pets & 2.35 & 0.47 & 0.16 & 0.99 & 0.01 & 0.0001 \\
\hline 6. & Hired community Guard & 2.68 & 0.59 & 0.19 & 1.15 & 0.14 & 0.02 \\
\hline 7. & $\begin{array}{l}\text { Possession and use of } \\
\text { Gun }\end{array}$ & 1.75 & 0.36 & 0.07 & 0.73 & 0.27 & 0.07 \\
\hline 8. & Alarm system & 1.97 & 0.44 & 0.12 & 0.84 & 0.16 & 0.03 \\
\hline 9. & $\begin{array}{l}\text { Special window and door } \\
\text { locks }\end{array}$ & 2.67 & 0.63 & 0.18 & 1.16 & 0.16 & 0.03 \\
\hline 10. & $\begin{array}{ll}\text { Closed } & \text { Circuit } \\
\text { Television } & \\
\end{array}$ & 1.95 & 0.44 & 0.09 & 0.83 & 0.17 & 0.03 \\
\hline & Total & 23.53 & 4.94 & 1.43 & 9.97 & & \\
\hline & EDCMI & 2.35 & 0.49 & 0.14 & $* 1.0$ & & \\
\hline
\end{tabular}

Source: Author's Field Survey, 2016

\section{CONCLUSION AND RECOMMENDATIONS}

It was observed that smoking, theft and truancy were the prominent delinquencies in the whole study area but smoking, cultism and reckless endangerment were the dominant juvenile delinquencies in the high, medium and low residential density area respectively. Delinquencies such as loitering, violence and rioting were minimal among others in the three residential areas. The observed variation in the incidence of juvenile delinquency is significant among the three residential areas in the Estate. The major perceived contributing factors to juvenile delinquency in Ijaiye Low Cost Housing Estate were influence of peer group, social and entertainment media; parents and teachers not paying enough attention to children, the absence of functioning parks and sporting facilities.

Residents living in the high density area of Ijaiye Low Cost Housing Estate have high level of fear of their properties being carted away by criminals, 'fear of being attacked late in the night' while in the medium density zone fear of being attacked late in the night, fear of being attacked early in the morning and fear of being raped were prominent. Adult residents living in the low density had feelings of property being stolen and fear of unknown. The residents of the high density area had high level of fear of juvenile delinquency than the remaining two densities as well as the study area taken as a whole. The pattern of fear of crime events observed in Ijaiye Low Cost Housing Estate was not at variance with the perceived level of incidence of juvenile delinquency. The level of incidence and fear of delinquency decreased from the high to the low density area. This was considered a normative; people who experienced high level of delinquency would exercise high level of fear of such.

Residents of the three areas considered their building fence, hired community guard and the use of special 
window and door locks more effective in preventing and or controlling juvenile delinquencies. People whether victim of crime or not have created fortified prison for themselves within their homes all in a bid to wade off juvenile delinquency. Some even found it difficult to come out of their home for the fear of being attacked while some could not even sleep with both eyes closed at night. People daily fall victim of juvenile delinquency one way or the other and urban residents live in total fear. Despite these, most of the adult residents refused to relocate from the area due to fear of not finding another better covers. Thus residents lived with fear every day and were learning to cope with it. This has implication for policy formulation and future research work.

The study provided empirical evidences that residents of the three residential areas of a planned housing estate had different perception of the level of incidences, causes and effects of juvenile delinquencies. This implies that strategies or intervention targeted at addressing this maladjustment must reflect these differences. Areas of high incidences and impact should receive greater attention while not neglecting other areas. Any intervention should be done in collaboration with the residents so as to reflect their concerns. Planned residential environment as observed in this study does not indicate freedom from social ills such as juvenile delinquency and the associated fear. Then, while there are serious efforts at creating aesthetically pleasing, conducive and functional residential environment, it should be done to deter crime and there must be commensurable steps at reorienting people towards a life of peace and orderliness. This is part of creating a safe and sustainable city.

\section{REFERENCES}

Abodunrin, F.O. (2004). Spatio-Temporal Variation and Residents Response to Crime in Ogbomoso. M.Tech, Dissertation Department of Urban and Regional Planning, Ladoke Akintola University of Technology.

Adigun, F. O. (2012). Spatio-temporal Analysis of Urban Crime in Selected Nigerian Cities. Ph. D dissertation, Department of Urban and Regional Planning, Ladoke Akintola University of Technology, Ogbomoso.

Afon, A.O. (2001). "Resident Diversity Factor in the Perception of and Response to Fear of Crime in Nigeria". Paper presented at the International Conference on Security, Segregation and Social Networks in West Africa Cities $19^{\text {th }}-20^{\text {th }}$ Centuries, held at the International Centre for African Studies (IFRA) University of Ibadan.

Agbola, Tunde (1997). Architecture of Fear, Urban Design and Construction Response to Urban Violence in Lagos, Nigeria. Ibadan. IFRA.

Agbola Tunde (2002): "Urban Violence, Urban Security and the Challenges of Governance. The Evolving Disturbing Scenario from Abuja Nigeria." Paper Presented at the 33" Annual Conference of Nigeria Institute of Town Planners held at Ilorin $30^{\text {th }}$ Oct. - $1^{\text {st }}$ Nov, pp 61-82.

Aguilar, Sroufe, Egeland, \& Carlson, 2000 Enhanced Services and Stipends for Foster Parents: Effects on Retention Rates and Outcomes for Children. Child Welfare 5, 387-401[DHHS Publication No. (ADM) 871537].

Albert, I.O. (1994): Urban Violence in Contemporary Africa: Some Theoretical Exploration. In Albert, I.O, Adisa, J Agbola T. and Herault, G. (eds) Urban Management and Urban Violence in Africa. Vol. 1 pp.9-20 Ibadan. IFRA

Charron, M. (2012). Neighbourhood Characteristics and the Distribution of Crime in Toronto: Additional Analysis on Youth Crime. Crime and Justice Research Paper Series. Ottawa, ON: Statistics Canada. Dictionary Thesaurus Accessed 01-07-2013

Dodge (2003). "A Biopsychosocial Model of the Development of Chronic Conduct Problems in Adolescence". Developmental Psychology 39: 349-371. doi:10.1037/0012-1649.39.2.349.

Farrington, D. P. (2002). "Developmental Criminology and Risk-focused Prevention". In Maguire, M. et al. The Oxford Handbook of Criminology (3rd ed.). Oxford: Oxford University Press. ISBN 0199256098.

Mack et al., (2006) Poverty and the effect on children and parent.University of Chicago Press, Chicago.

Mandara and Murray, (2006) Curbing Residential Burglary Through Environmental Design. Unpublished MURP dissertation, Centre of Urban Research and Planning (CURP). University of Ibadan

Moffitt (2006). "Life Course Persistent Versus Adolescent Limited Antisocial Behavior". In Cicchetti, D.; Cohen, D. Developmental Psychopathy (2nd ed.). New York: Wiley.

Obateru, O. I. (1994): Planning the City to Mitigate, Urban Violence. In Albert, O.I., Adisa, J., Agbola, T. and Herault G. (eds) Urban Management and Urban Violence in Africa. Vol. 1 Ibadan : IFRA

Oredein, Simisola, A. (2006): An Assessment of Residents Response to Crime in Abuja, FCT. B.Tech Dissertation, Department of Urban and Regional Planning, Ladoke Akintola University of Technology.

Scott (2009). "The legal regulation of adolescence". In Lerner, R.; Steinberg, L. Handbook of Adolescent psychology 2 (3rd ed.). New York: Wiley. pp. 345-371. ISBN 9780470149225

Shaw, C. D. and McKay, H. (1942). (Revised 1969) Juvenile Deliquency and Urban Areas. Chicago: University of Chicago Press.

Thornberry et al (2004)" Youth gangs in International Perspectives".University of Chicago Press, Chicago.

Walklate, S (2003). Understanding Criminology - Current Theoretical Debates, 2nd edition, $\quad$ Maidenhead: Open University Press. 